\title{
The novel inosine analogue, INO-2002, protects against diabetes development in multiple low-dose streptozotocin and non-obese diabetic mouse models of type I diabetes
}

\author{
Jon G Mabley, Pal Pacher ${ }^{1}$, Kanneganti G K Murthy², William Williams², Garry J Southan², \\ Andrew L Salzman ${ }^{2}$ and Csaba Szabo ${ }^{3}$ \\ School of Pharmacy and Biomolecular Sciences, University of Brighton, Cockcroft Building, Lewes Road, Brighton BN2 4GJ, UK \\ ${ }^{1}$ Section on Oxidative Stress Tissue Injury, Laboratory of Physiological Studies, National Institutes of Health/NIAAA, 5625 Fishers Lane, Bethesda, Maryland \\ 20892-9413, USA \\ ${ }^{2}$ Inotek Pharmaceuticals Corporation, 100 Cummings Center, Beverly, 01915 Massachusetts, USA \\ ${ }^{3}$ Department of Surgery, University of Medicine and Dentistry of New Jersey-New Jersey Medical School, 185 South Orange Avenue, Newark, New Jersey \\ 07103, USA \\ (Correspondence should be addressed to J G Mabley; Email: j.g.mabley@brighton.ac.uk)
}

\begin{abstract}
Endogenous purines including inosine have been shown to exert immunomodulatory and anti-inflammatory effects in a variety of disease models. The dosage of inosine required for protection is very high because of the rapid metabolism of inosine in vivo. The aim of this study was to determine whether a metabolic-resistant purine analogue, INO-2002, exerts antiinflammatory effects in two animal models of type I diabetes. Type I diabetes was induced chemically with streptozotocin or genetically using the non-obese diabetic (NOD) female mouse model. Mice were treated with INO-2002 or inosine as required at 30,100, or $200 \mathrm{mg} / \mathrm{kg}$ per day, while blood glucose and diabetes incidence were monitored. The effect of INO2002 on the pancreatic cytokine profile was also determined. INO-2002 reduced both the hyperglycaemia and incidence of diabetes in both streptozotocin-induced and spontaneous
\end{abstract}

diabetes in NOD mice. INO-2002 proved to be more effective in protecting against diabetes than the naturally occurring purine, inosine, when administered at the same dose. INO2002 treatment decreased pancreatic levels of interleukin (IL)-12 and tumour necrosis factor- $\alpha$, while increasing levels of IL-4 and IL-10. INO-2002 also reduced pancreatic levels of the chemokine MIP-1 $\alpha$. The inosine analogue, INO-2002, was protected more effectively than the naturally occurring purine, inosine, against development of diabetes in two separate animal models. INO-2002 exerts protective effects by changing the pancreatic cytokine expression from a destructive Th1 to a protective Th2 profile. The use of analogues of inosine such as INO-2002 should be considered as a potential preventative therapy in individuals susceptible to developing type I diabetes. Journal of Endocrinology (2008) 198, 581-589

\section{Introduction}

Type I diabetes is a disease characterized by the specific destruction of insulin-producing $\beta$-cells in the pancreatic islets of Langerhans by the immune system (Bach 1994). Immune cells, particularly macrophages and T-cells, invade the islet and these cells are cytotoxic to islet $\beta$-cells in part by producing cytokines and free radicals (Rabinovitch \& Suarez-Pinzon 1998). It has been proposed that the insulitis lesion is $\beta$-cell destructive when Th1 cytokines (IL-12, interferon (IFN)- $\gamma$, IL-1 and tumour necrosis factor (TNF)- $\alpha$ ) produced by isletinfiltrating macrophages and T-cells dominate over Th2 cytokines (IL-4 and IL-10; Rabinovitch 1998).

Purine nucleosides, such as inosine, are low molecular weight molecules that are involved in a wide variety of intracellular biochemical processes (Hasko et al. 2004). Additionally, nucleosides function as extracellular signalling molecules and, although inosine is only present at low levels in the extracellular space, metabolically stressful conditions such as nflammation dramatically increase the concentration (Hasko et al. 2004). Inosine has proved to be a powerful immunomodulatory agent both in vitro (Hasko et al. 2000, Marton et al. 2001) and in vivo (Hasko et al. 2000, Garcia Soriano et al. 2001, Liaudet et al. 2001, 2002, Mabley et al. 2003a,b, Darlington \& Gann 2005, Schneider \& Klein 2005, Szabo et al. 2006). Inosine treatment reduces the production of inflammatory cytokines by murine and human macrophages stimulated by lipopolysaccharide (LPS) in addition to the provided protective effects on both intestinal and vascular function in murine models of endotoxic shock (Hasko et al. 2000, Garcia Soriano et al. 2001). Inosine also attenuates the course of chronic autoimmune inflammatory diseases including type I diabetes (Mabley et al. 2003b) and colitis (Mabley et al. 2003a); the protective effects mediated by inosine reduce production of pro-inflammatory cytokines and chemokines. 
However, the high dosage of inosine required for protection would prove problematic to administer therapeutically.

The likely hypothesis explaining the high doses of inosine required is the short half-life of inosine in vivo due to its rapid metabolism by purine nucleoside phosphorylase to hypoxanthine, which is broken down via xanthine to uric acid by xanthine oxidase (Hasko et al. 2004). Therefore, development of a purine analogue resistant to metabolism may overcome the dosage issue associated with inosine and prove effective in a clinical setting; INO-2002 was developed to be such an analogue.

There are two primary murine models of type I diabetes: the multiple low-dose streptozotocin (MLDS) model and the spontaneous non-obese diabetic (NOD) mouse model. The MLDS model of diabetes is characterized by a progressive hyperglycaemia and an insulitis similar to that observed in human subjects with recent-onset type I diabetes (Like \& Rossini 1976, Rossini et al. 1978). Though not an autoimmune-mediated destruction of the $\beta$-cell, the inflammatory system is ultimately responsible for $\beta$-cell death following MLDS (Szkudelski 2001). MLDS-induced diabetes has shown to be T-cell mediated (Harlan et al. 1995) and blockage of chemokines prevented MLDS induction of diabetes via reduced islet immune cell infiltration (Martin et al. 2007). The NOD mouse model also shares clinical, serological and histoimmunological features with human type I diabetes in addition to being an autoimmune destruction of the $\beta$-cells (Atkinson \& Leiter 1999). Both models have been used extensively to study preventative therapies for type I diabetes (Atkinson \& Leiter 1999, Mabley et al. 2001b). A variety of procedures and therapies that delete, suppress or modulate functions of the immune system cells can block both the inflammatory response in the MLDS model as well as the autoimmune response against islet $\beta$-cells in the NOD mouse (Chatenoud et al. 1997, Ryu et al. 2001). This study was undertaken to evaluate INO-2002 as a metabolicresistant purine analogue and as such a possible therapy for modulating the development of type I diabetes.

\section{Materials and Methods}

\section{Materials}

Reagents were obtained from the following sources. Amplex red xanthine/xanthine oxidase assay kits were obtained from Molecular Probes (Eugene, OR, USA). Streptozotocin and sodium citrate were obtained from Sigma. BALB/c and NOD mice were purchased from Taconic (Germantown, NY, USA). Insulin ELISA kits were obtained from Alpco (Windham, NH, USA) and insulin RIA kits were from Linco Research (St Charles, MO, USA). Urine glucose TesTape was from Eli Lilly, and a One-Touch II hospital blood glucose meter was from Lifescan (Johnson \& Johnson company, Milpitas, CA, USA). Cytokine ELISA kits were from R\&D Systems (Minneapolis, MN, USA).
Measurement of INO-2002 breakdown by purine-metabolizing enzymes

The conversion of INO-2002 to inosine by nucleoside phosphorylase and $5^{\prime}$-nucleotidase to form hypoxanthine was measured and compared with that of inosine and inosine monophosphate (IMP). Inosine, IMP or INO-2002 (1, 3, 10 or $30 \mu \mathrm{M})$ was incubated either alone or with nucleoside phosphorylase $(500 \mathrm{mU} / \mathrm{ml}) \pm 5^{\prime}$-nucleotidase $(500 \mathrm{mU} / \mathrm{ml})$ for $30 \mathrm{~min}$ at $37^{\circ} \mathrm{C}$. Hypoxanthine $(1,3,10$ and $30 \mu \mathrm{M})$ was used as a positive control. Hypoxanthine concentrations following the incubation period were determined using the Amplex red xanthine/xanthine oxidase assay kit.

\section{Induction of diabetes}

All animal experiments were carried out in accordance with the guidelines published by the NIH in 'Principles of Laboratory Animal Care' (NIH publication no. 85-23, revised 1985), 'The UFAW handbook on the Care and management of Laboratory Animals' and FRAME's guidelines on use of laboratory animals. Male BALB/c mice were treated with streptozotocin $(40 \mathrm{mg} / \mathrm{kg}$ dissolved in citrate buffer $(\mathrm{pH} 4 \cdot 5)$ ) or vehicle (citrate buffer) i.p. for 5 consecutive days. Mice were treated every day starting on day 1 with either INO-2002, inosine (30, 100 or $200 \mathrm{mg} / \mathrm{kg}$ per day) or vehicle (water) orally by gavage. Blood glucose was measured on days 1, 7, 14 and 21 from blood obtained from the tail vein. Hyperglycaemia was defined as a nonfasting blood glucose level $\geq 200 \mathrm{mg} / \mathrm{dl}$. Cumulative incidence of diabetes was calculated as a percentage of hyperglycaemic mice at each time point. Samples of pancreas were taken following killing on day 21 for biochemical and cytokine assays (Mabley et al. 2005).

Female NOD mice were purchased at 4 weeks of age and allowed to acclimatize to our animal facility for 1 week prior to daily treatment with INO-2002 (30 or $100 \mathrm{mg} / \mathrm{kg}$ per day, orally by gavage) commencing at 5 weeks of age. In the first study, spontaneous diabetes incidence was monitored until 30 weeks of age. Urine glucose levels were checked daily and a mouse was defined as diabetic following 3 days of glucosuria and a blood glucose level on the third day $\geq 200 \mathrm{mg} / \mathrm{dl}$. In a second study, female NOD mice were treated in the same way and, when the mice reached 18 weeks of age, pancreas samples and serum were taken from normoglycaemic NOD mice for biochemical analysis.

Determination of pancreatic or serum insulin and cytokine levels

Insulin contents in pancreata of $\mathrm{BALB} / \mathrm{c}$ or NOD mice were determined from a pancreas sample, taken immediately following killing, which was homogenized in acidified ethanol (75\% ethanol, $1.5 \% 12 \mathrm{~mol} / 1 \mathrm{HCl}$ and $23.5 \%$ $\mathrm{H}_{2} \mathrm{O}$ ), then incubated for $72 \mathrm{~h}$ at $4^{\circ} \mathrm{C}$ and centrifuged. Care was taken to remove samples from the same location of the pancreas (body) to avoid differences between the regions 
A

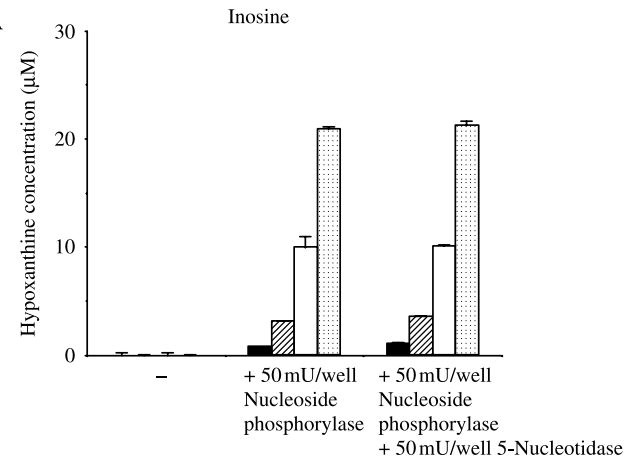

$\mathrm{B}$

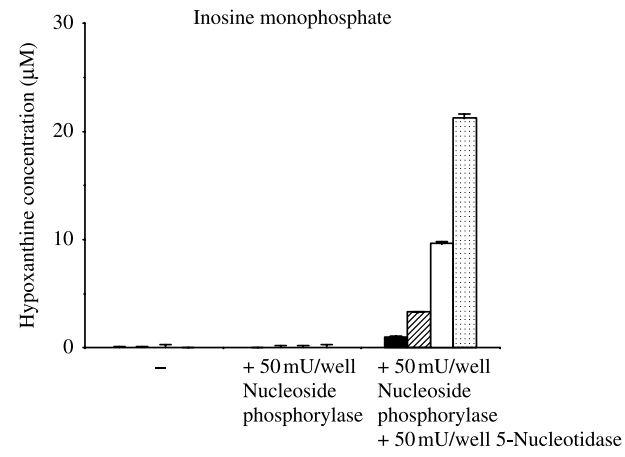

$\mathrm{C}$

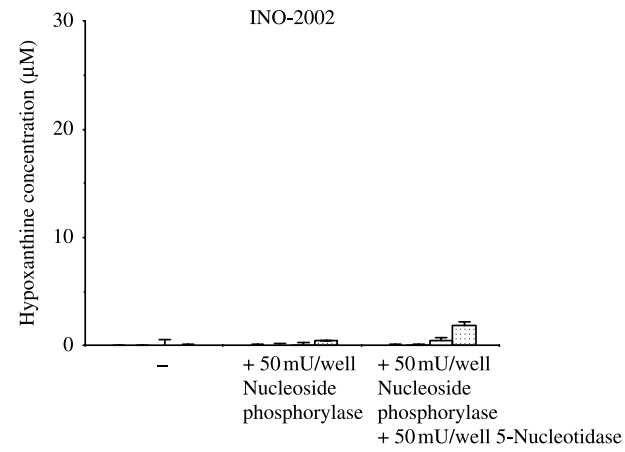

D

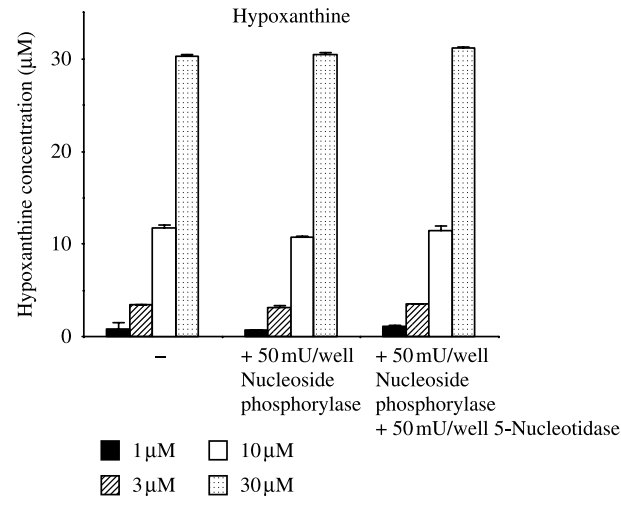

of the pancreas in regards to insulin content. The insulin content of the supernatant was determined using an ELISA kit (Alpco). Pancreatic insulin content was expressed as ng insulin/mg protein, which was determined by the Bradford assay (Bradford 1976). Serum insulin levels were determined using the same ELISA kit and expressed as ng insulin $/ \mathrm{ml}$.

Cytokine levels in pancreas were determined from a pancreas sample snap frozen in liquid nitrogen. The biopsies were homogenized in $700 \mu \mathrm{l}$ of a Tris- $\mathrm{HCl}$ buffer containing protease inhibitors (Mabley et al. 2002), centrifuged for $30 \mathrm{~min}$, and then the supernatant was removed and frozen at $-80{ }^{\circ} \mathrm{C}$ until assay. Cytokine contents in pancreas were determined using specific ELISA kits (R\&D Systems) and expressed as pg cytokine protein/mg protein.

\section{Statistical analyses}

Data are presented as means \pm s.E.M. Statistical analysis was performed using the ANOVA with Bonferroni's correction, Fisher's exact test or Student's $t$-test as appropriate; $P<0 \cdot 05$ was considered significant.

\section{Results}

INO-2002 is more resistant to metabolizing enzymes than inosine or inosine mono-phosphate

In the absence of the purine-metabolizing enzymes, nucleoside phosphorylase or $5^{\prime}$-nucleotidase, no hypoxanthine was formed from inosine monophosphate (IMP) or INO-2002 (Fig. 1A-C). Nucleoside phosphorylase $(500 \mathrm{mU} / \mathrm{ml})$ metabolized inosine to hypoxanthine (Fig. 1A) but had no effect on IMP or INO-2002 (Fig. 1B and C). A combination of nucleoside phosphorylase $(500 \mathrm{mU} / \mathrm{ml})$ and $5^{\prime}$-nucleotidase $(500 \mathrm{mU} / \mathrm{ml})$ metabolized IMP to hypoxanthine (Fig. 1B) but had no effect on INO-2002 (Fig. 1C). Hypoxanthine was included in the assay as a positive control to demonstrate hypoxanthine can be detected under all conditions (Fig. 1D).

\section{INO-2002 protects against MLDS-induced hyperglycaemia and diabetes}

MLDS treatment induced a progressive hyperglycaemia (Fig. 2A) over a 21-day period with a corresponding increase

Figure 1 INO-2002 is protected from breakdown by the purinemetabolizing enzymes nucleoside phosphorylase and $5^{\prime}$-nucleotidase. In the absence of purine-metabolizing enzymes, no hypoxanthine was formed from inosine, inosine monophosphate (IMP) or INO-2002. Incubation with nucleoside phosphorylase $(500 \mathrm{mU} / \mathrm{ml})$, which catalyses the breakdown of purines to hypoxanthine, was able to metabolize inosine to hypoxanthine over a 30 min period but had no effect IMP or INO-2002. Addition of $5^{\prime}$-nucleotidase $(500 \mathrm{mU} / \mathrm{ml})$, an enzyme that removes groups from the $5^{\prime}$ position of the purine, enabled the metabolism of IMP to hypoxanthine but again had no effect on INO-2002. Results are expressed as mean \pm s.E.M. from six separate reactions. 

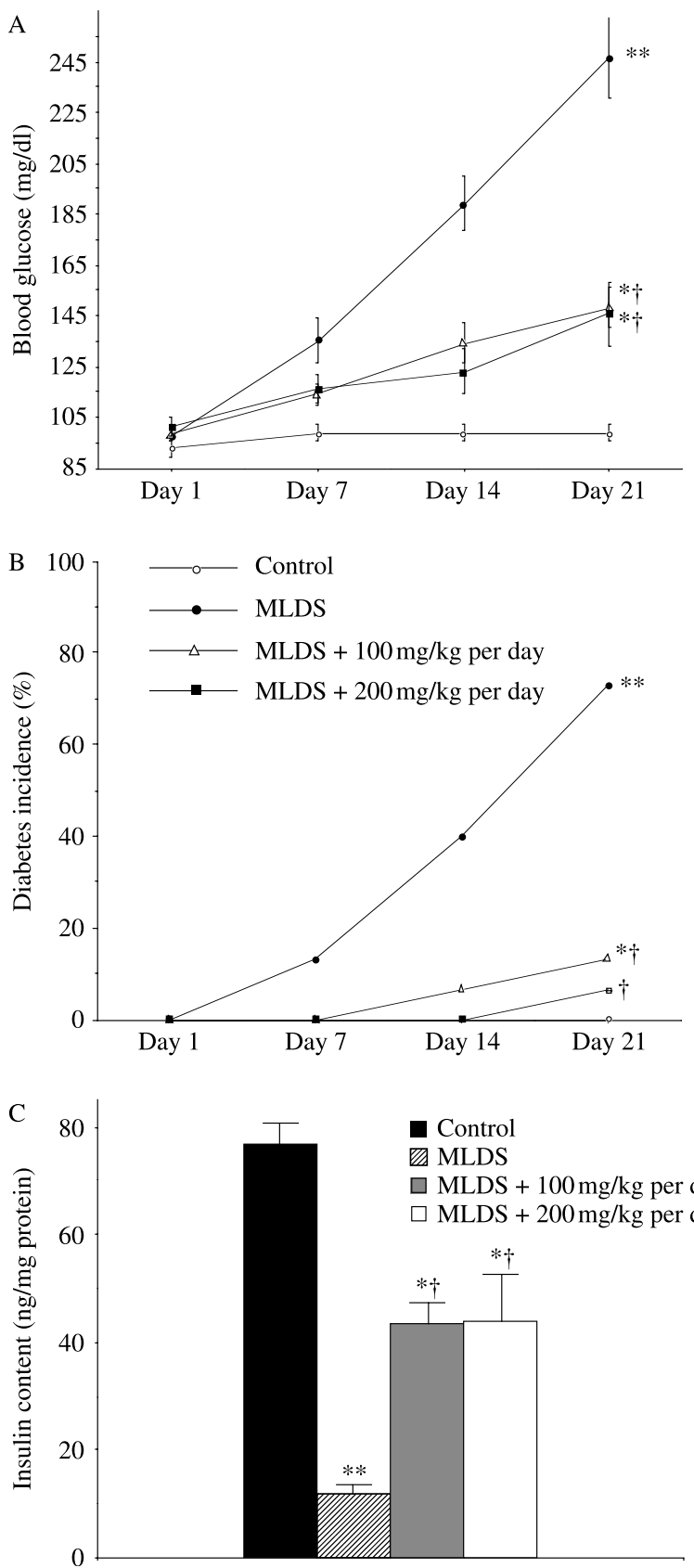

Figure 2 Daily treatment with INO-2002 (100 or $200 \mathrm{mg} / \mathrm{kg}$ per day) for 21 days decreases hyperglycaemia (A), incidence of diabetes (B) and loss of pancreatic insulin content $(C)$ following MLDS-treatment of BALB/C mice. Diabetes incidence is expressed as a cumulative percentage of mice with a blood glucose $\geq 200 \mathrm{mg} / \mathrm{dl}$. Results are mean \pm s.E.M. with 15 mice per experimental group. ${ }^{*} P<0 \cdot 05,{ }^{* *} P<0 \cdot 01$ versus vehicle-treated mice; ${ }^{+} P<0.05$ versus MLDS-treated mice.

in diabetes incidence (blood glucose $\geq 200 \mathrm{mg} / \mathrm{dl}$ ) being observed (Fig. 2B). INO-2002 at both 100 and $200 \mathrm{mg} / \mathrm{kg}$ per day significantly reduced the rise in mean blood glucose level over the 21-day period (Fig. 2A). Additionally,
INO-2002 at 100 or $200 \mathrm{mg} / \mathrm{kg}$ per day decreased the incidence of diabetes on day 21 from 73 to 13 and $6 \%$ respectively (Fig. 2B). Pancreas insulin content was significantly reduced by MLDS treatment on day 21 (Fig. 2C), an affect attenuated by both 100 and $200 \mathrm{mg} / \mathrm{kg}$ per day INO2002 (Fig. 2C).

MLDS treatment significantly increased pancreatic levels of inflammatory Th1 cytokines (IL-12 and TNF- $\alpha$ ) on day 21 (Table 1), with INO-2002 treatment preventing the increase in both IL-12 and TNF- $\alpha$ (Table 1). MLDS treatment alone had no effect on the pancreatic levels of the Th2 cytokines, IL-4 and IL-10 (Table 1), however, with INO-2002 treatment the pancreatic levels of IL-4 and IL-10 were significantly increased (Table 1).

\section{Inosine versus INO-2002}

In a separate experiment, INO-2002 and inosine efficacy were directly compared at $30 \mathrm{mg} / \mathrm{kg}$ per day in the MLDS model of diabetes. MLDS treatment again increases blood glucose levels over the 21-day period (Fig. 3A) with a diabetic incidence on day 21 of $84 \%$ (Fig. 3B). Inosine $(30 \mathrm{mg} / \mathrm{kg}$ per day) had no effect on hyperglycaemic levels or diabetic incidence on day 21 when compared with MLDS alone; $249 \pm 13$ vs $232 \pm 16 \mathrm{mg} / \mathrm{dl}$ (Fig. $3 \mathrm{~A}$ ) and 84 vs $73 \%$ (Fig. 3B). However, INO-2002 (30 mg/kg per day) significantly attenuated the rise in blood glucose levels on day 21 when compared with MLDS from $249 \pm 13$ to $178 \pm$ $16 \mathrm{mg} / \mathrm{dl}$ and reduced the diabetes incidence from 84 to $40 \%$ (Fig. 3A and B). Blood glucose and diabetes incidence levels in INO-2002-treated mice were also significantly lower than in mice treated with inosine (Fig. 3A and B). Similar protective effects were observed on pancreas insulin content (Fig. 3C) with INO-2002 again proving more effective than inosine in attenuating the MLDS-mediated loss of insulin content (Fig. 3C).

INO-2002 reduces the incidence of diabetes, inhibition of $\beta$-cell function and loss of $\beta$-cell mass in female NOD mice

Female NOD mice were treated daily from the age of 5 weeks with either INO-2002 (30 or $100 \mathrm{mg} / \mathrm{kg}$ per day) or vehicle (water). INO-2002 treatment delayed the onset of diabetes from 11 to 14 and 16 weeks for 30 and $100 \mathrm{mg} / \mathrm{kg}$ per day respectively (Fig. 4A). Diabetes incidence at week 20 was $60 \%$ in the vehicle-treated group and this was reduced to 25 and $15 \%$ for 30 and $100 \mathrm{mg} / \mathrm{kg}$ per day INO-2002 treatment respectively (Fig. 4A). This protection continued throughout the experiment with incidence at 30 weeks of $80 \%$ in the vehicle-treated group significantly reduced to 55 and $35 \%$ for 30 and $100 \mathrm{mg} / \mathrm{kg}$ per day INO-2002 treatment respectively.

Pancreatic insulin content at 18 weeks of age was significantly increased in the INO-1001-treated groups from $16 \pm 5 \mathrm{ng} / \mathrm{mg}$ protein to $35 \pm 8$ and $48 \pm 10$ for 30 and $100 \mathrm{mg} / \mathrm{kg}$ per day respectively (Fig. 4B). Similarly serum insulin levels at 18 weeks of age were increased by 170 and 
Table 1 INO-2002 (100 or 200 mg/kg per day) prevents the multiple low-dose streptozotocin (MLDS)-induced increases in tumour necrosis factor (TNF)- $\alpha$ and IL-12 (p40) in pancreata of BALB/C mice, while increasing the levels of IL-4 and IL-10. Results are mean \pm s.E.M. $(n=10$ mice per group)

\begin{tabular}{|c|c|c|c|c|}
\hline & Control & MLDS & $\mathbf{M L D S}+\mathbf{1 0 0} \mathrm{mg} / \mathrm{kg}$ per day & $\mathbf{M L D S}+\mathbf{2 0 0} \mathrm{mg} / \mathrm{kg}$ per day \\
\hline \multicolumn{5}{|c|}{ Cytokine (pg/mg protein) } \\
\hline TNF- $\alpha$ & $3 \cdot 1 \pm 0 \cdot 3$ & $7 \cdot 96 \pm 0.6^{*}$ & $3 \cdot 85 \pm 0 \cdot 4^{\neq}$ & $3 \cdot 49 \pm 0 \cdot 46^{\neq}$ \\
\hline IL-12 & $3 \cdot 32 \pm 0 \cdot 66$ & $8.93 \pm 0.98^{*}$ & $4 \cdot 73 \pm 0 \cdot 3^{+}$ & $3 \cdot 24 \pm 0 \cdot 36^{\neq}$ \\
\hline IL-4 & $2 \cdot 24 \pm 0 \cdot 27$ & $2 \cdot 85 \pm 0 \cdot 25$ & $5 \cdot 39 \pm 0 \cdot 16^{*,+}$ & $4 \cdot 94 \pm 0 \cdot 19^{*,+}$ \\
\hline IL-10 & $3 \cdot 56 \pm 0 \cdot 38$ & $3 \cdot 6 \pm 0 \cdot 35$ & $7 \cdot 37 \pm 0 \cdot 83^{*,+}$ & $8 \cdot 57 \pm 0 \cdot 61^{*, \neq}$ \\
\hline
\end{tabular}

${ }^{*} P<0 \cdot 01$ versus vehicle-treated mice and ${ }^{\dagger} P<0 \cdot 05,{ }^{\ddagger} P<0 \cdot 01$ versus MLDS-treated mice.

$194 \%$ respectively for 30 and $100 \mathrm{mg} / \mathrm{kg}$ per day INO-2002 when compared with vehicle-treated mice (Fig. 4C). Pancreatic levels of the chemokine MIP-1 $\alpha$ and Th1 cytokines, TNF- $\alpha$ and IL-12, were significantly lower in NOD mice treated with INO-2002 when compared with vehicle (Table 2). By contrast, pancreatic levels of IL-10 in INO-2002-treated mice were significantly higher than those measured in vehicle-treated mice (Table 2).

\section{Discussion}

Our study demonstrates that the novel purine analogue, INO-2002, is resistant to metabolic breakdown to hypoxanthine by both purine nucleoside phosphorylase and $5^{\prime}$-nucleotidase. Additionally, INO-2002 protects against diabetes development in two animal models of type I diabetes, MLDS-induced diabetes in male BALB/c mice and spontaneous diabetes in female NOD mice. We also found that the purine analogue of inosine, INO-2002, is more efficacious than naturally occurring inosine in attenuating type I diabetes when administered at the same dose. Previous reports had already demonstrated an antiinflammatory effect of inosine in a variety of disease models but at doses unachievable in a clinical setting. This study has shown that a chemical analogue of inosine, INO-2002, is a more effective anti-inflammatory agent with protective effects at doses lower than observed with inosine.

Previous work has shown that inosine dose dependently protected against MLDS-induced diabetes via conversion of the pancreatic cytokine profile from a predominantly Th1 expression to a Th2 expression (Mabley et al. 2003b). However, the protection was only observed with inosine at doses of $100 \mathrm{mg} / \mathrm{kg}$ per day or higher making its clinical application unlikely. INO-2002, however, was very effective at reducing diabetes incidence in the MLDS model, reducing incidence from 84 to $40 \%$ at $30 \mathrm{mg} / \mathrm{kg}$ per day, whereas inosine at the same concentration had very little effect with diabetes incidence remaining at $73 \%$. Indeed, when comparing INO-2002 at the higher doses to the previously published inosine results (Mabley et al. 2003b), a similar increased protection with INO-2002 is observed at 100 or $200 \mathrm{mg} / \mathrm{kg}$ per day, where diabetes incidence in the MLDS model is only 13 or $6 \%$ when compared with inosine and where incidence was double when compared with INO-2002 at the same dose at 30 and 13\% (Mabley et al. 2003b). INO2002 is therefore more effective at reducing diabetes incidence than inosine probably through its resistance to metabolism to hypoxanthine.

Inosine pranobex, a clinically used form of inosine, has to be administered at doses higher than $200 \mathrm{mg} / \mathrm{kg}$ per day (Wybran et al. 1981, Campoli-Richards et al. 1986). IMP has also been shown to be anti-inflammatory (Qiu et al. 2000, Li et al. 2007), an effect that may also be mediated through the pathways activated by inosine. Indeed, inhibition of IMP dehydrogenase (IMPDH) by mycophenolate mofetil (MMF) has proved effective in transplant rejection and also in a variety of autoimmune diseases (Allison \& Eugui 2000) including type I diabetes (Maksimovic-Ivanic et al. 2002, StosicGrujicic et al. 2002). It may be the cellular increase in IMP accounts for the anti-inflammatory effects of IMPDH inhibitors such as MMF. However, though IMP is more resistant to breakdown than inosine as before, it can be metabolized to hypoxanthine by nucleoside phosphorylase following removal of the phosphate group by $5^{\prime}$-nucleotidase; therefore, a purine analogue resistant to both nucleoside phosphorylase and $5^{\prime}$-nucleotidase would be desirable for a therapeutic agent. We have demonstrated here that INO2002 is such an analogue, resistant to being broken down into hypoxanthine by nucleoside phosphorylase alone or in combination with $5^{\prime}$-nucleotidase. This resistance to breakdown may explain why INO-2002 is more effective than inosine in protecting against MLDS-induced diabetes and also suggests it would be more potent than IMP.

The mechanism of action of INO-2002 in protecting against type I diabetes appears similar to that of inosine reduction of pancreatic levels of the Th1 cytokines (IL-12 and TNF- $\alpha$ ) while increasing the levels of Th2 cytokines (IL-4 and IL-10). Both TNF- $\alpha$ and IL-12 have been implicated in $\beta$-cell functional inhibition, destruction and autoimmune diabetes (Rabinovitch \& Suarez-Pinzon 1998, Eizirik \& Darville 2001). IL-12 expression has been correlated with development of diabetes in the NOD mouse (Rabinovitch et al. 1996), and treatment of NOD mice with an IL-12 antagonist suppressed diabetes development and decreased pancreatic expression of mRNA for IFN- $\gamma$ (Rothe et al. 

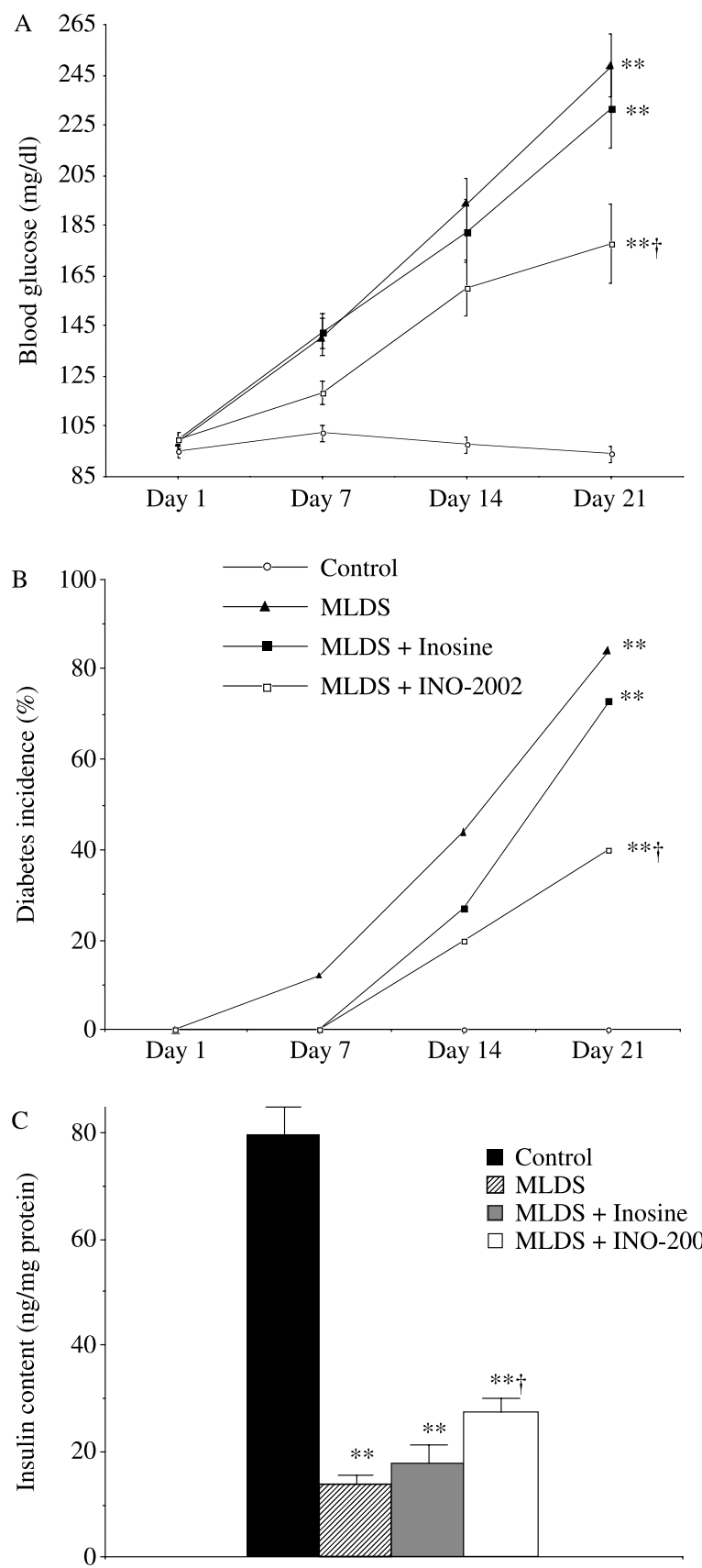

Figure 3 Comparison between INO-2002 and inosine $(30 \mathrm{mg} / \mathrm{kg}$ per day) on hyperglycaemia (A), incidence of diabetes (B) and loss of pancreatic insulin content (C) following MLDS-treatment of $\mathrm{BALB} / \mathrm{c}$ mice. Diabetes incidence is expressed as a cumulative percentage of mice with a blood glucose $\geq 200 \mathrm{mg} / \mathrm{dl}$. INO-2002 but not inosine at $30 \mathrm{mg} / \mathrm{kg}$ per day protected mice from MLDSmediated hyperglycaemia, diabetes incidence and loss of pancreatic insulin content. Results are mean \pm s.E.M. with 11-15 mice per experimental group. ${ }^{* *} P<0 \cdot 01$ versus vehicle-treated mice; ${ }^{+} P<0.05$ versus MLDS-treated mice.
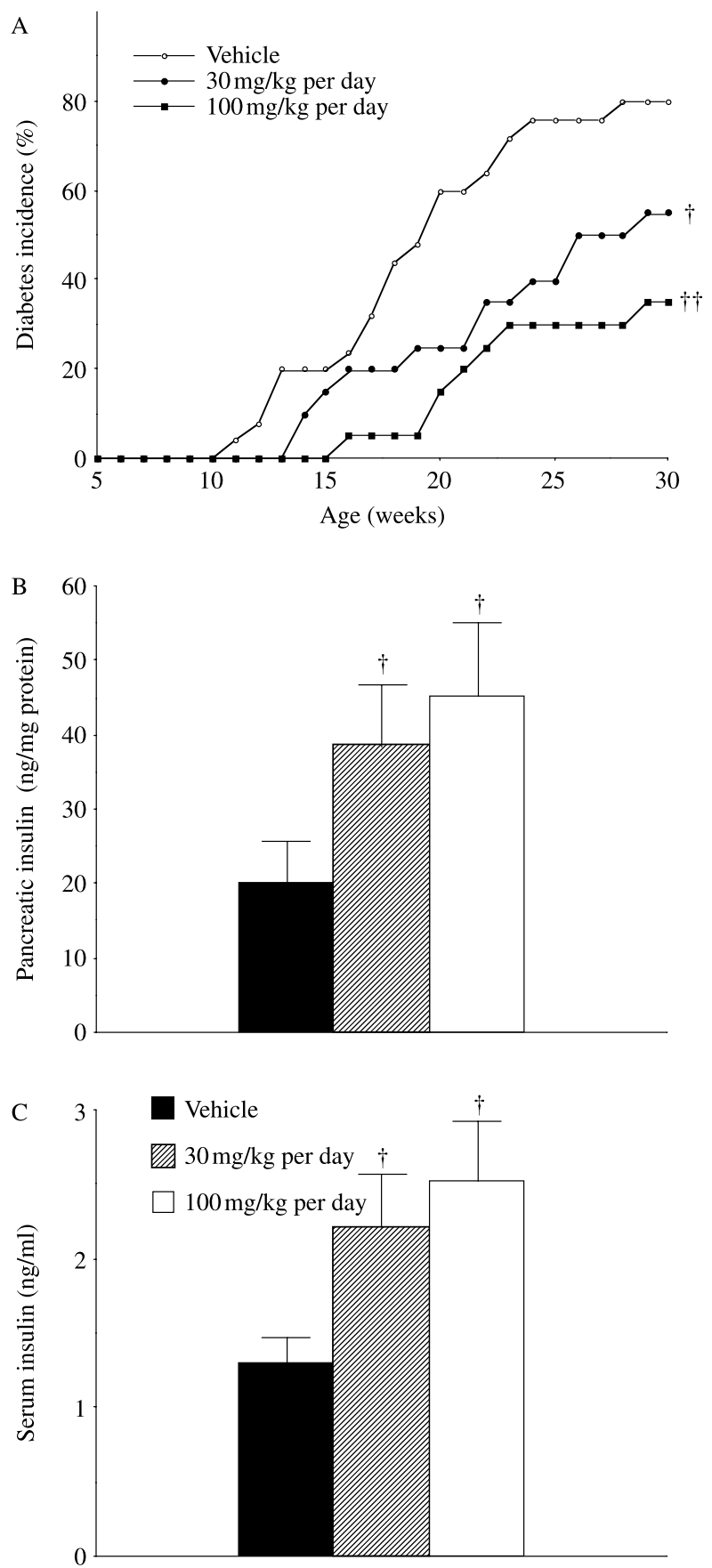

Figure 4 Daily INO-2002 (30 or $100 \mathrm{mg} / \mathrm{kg}$ per day orally) treatment starting at 5 weeks of age decreases the incidence of diabetes (A), increases pancreatic (B) and serum levels of insulin (C) when compared with vehicle-treated female NOD mice. Results are mean \pm S.E.M. with 20 mice per experimental group ${ }^{\dagger} P<0 \cdot 05$, ${ }^{\ddagger} P<0 \cdot 01$ versus vehicle-treated mice at 30 weeks of age. 
Table 2 Chemokine and cytokine levels in the pancreata of 18-week-old normoglycaemic female non-obese diabetic (NOD) mice treated with either vehicle or INO-2002 at 30 or $100 \mathrm{mg} / \mathrm{kg}$ per day from 5 weeks of age. INO-2002 significantly dose dependently reduced levels of MIP- $1 \alpha$, TNF- $\alpha$ and IL-12 (p40), while increasing levels of IL-10. Results are mean \pm S.E.M. $(n=10$ mice per group)

\begin{tabular}{|c|c|c|c|}
\hline & Vehicle & $\begin{array}{l}\text { INO-2002 } 30 \\
\text { mg/kg per day }\end{array}$ & $\begin{array}{l}\text { INO-2002 } 100 \\
\text { mg/kg per day }\end{array}$ \\
\hline \multicolumn{4}{|c|}{ Cytokine (pg/mg protein) } \\
\hline MIP-1 $\alpha$ & $2 \cdot 27 \pm 0 \cdot 19$ & $1 \cdot 37 \pm 0 \cdot 25^{*}$ & $0 \cdot 88 \pm 0 \cdot 14^{*}$ \\
\hline TNF- $\alpha$ & $4 \cdot 33 \pm 0 \cdot 43$ & $2 \cdot 87 \pm 0 \cdot 3^{*}$ & $2 \cdot 63 \pm 0 \cdot 51^{*}$ \\
\hline IL-12 & $11 \cdot 97 \pm 2 \cdot 03$ & $7 \cdot 88 \pm 0 \cdot 87$ & $5 \cdot 24 \pm 0 \cdot 67^{*}$ \\
\hline IL-10 & $2 \cdot 8 \pm 0 \cdot 3$ & $5 \cdot 81 \pm 1^{*}$ & $8 \cdot 48 \pm 0 \cdot 8^{+}$ \\
\hline
\end{tabular}

$* P<0 \cdot 05,{ }^{\dagger} P<0 \cdot 01$ versus vehicle-treated mice.

1997). In addition to decreasing pancreatic levels of Th1 cytokines (IL-12 and TNF- $\alpha$ ), INO-2002 increased pancreatic levels of the Th2 cytokines, IL-4 and IL-10, in mice with MLDS-induced diabetes. Previous in vitro experiments have demonstrated inhibition of Th1 cytokine mRNA expression and release by inosine, without any increase in Th2 cytokine production from macrophages stimulated with LPS (Hasko et al. 2000). In contrast, in endotoxemic mice, inosine not only significantly reduced Th1 cytokine levels but also increased the levels of Th2 cytokines (Hasko et al. 2000), suggesting that inosine's overall effect is a shift from a Th1- to a Th2-type cytokine profile. It has been shown in type I diabetes that shifting from a Th1 to a Th2 cytokine profile does not affect the insulitis observed but does change the insulitis from a destruction infiltration to a benign infiltration (Rabinovitch 1998, Rabinovitch \& Suarez-Pinzon 1998, Sia 2005).

INO-2002 was also effective at attenuating type I diabetes in the NOD mouse, a genetic model of disease with more in common to the human condition than the chemically induced MLDS model of diabetes (Atkinson \& Leiter 1999). INO-2002 was again more effective than inosine (Mabley et al. 2003b), significantly decreasing the incidence of diabetes in NOD mice even at $30 \mathrm{mg} / \mathrm{kg}$ per day as well as maintaining $\beta$-cell mass, as determined by pancreatic insulin content, and $\beta$-cell function, assessed by serum insulin levels. Again the protection observed with INO-2002 was associated with switch in the pancreatic cytokine profile from a Th1- to a Th2-dominant expression pattern. Inosine treatment proved only to reduce the Th1 cytokine levels in NOD pancreas and did not have a significant effect on Th2 cytokine levels though there was a trend to increase IL-10 levels (Mabley et al. 2003b), however, with INO-2002 there is a dose-dependent increase in NOD pancreas levels of IL-10.

INO-2002 also reduces NOD mouse pancreatic levels of MIP-1 $\alpha$, a chemokine responsible for innate and adaptive immune responses because of its ability to recruit, activate and co-stimulate T-cells and monocytes (Ward et al. 1998). Previously, increased levels of MIP-1 $\alpha$ in the NOD mouse pancreas was correlated with insulitis, and removing MIP-1 $\alpha$ either by gene disruption or neutralization using specific antibodies reduced diabetes incidence (Cameron et al. 2000), an effect also recently observed in the MLDS model of diabetes (Martin et al. 2007). Therefore, INO-2002 may be protective against type I diabetes through two pathways: first by altering the cytokine profile in the pancreas from Th1 and Th2 hence converting a destructive insulitis to a benign infiltration, and secondly by reducing the infiltration itself by decreasing chemokine expression. Interestingly, the reduction of MIP-1 $\alpha$ by inosine or INO-2002 appears to be ubiquitous in all the inflammatory conditions where purines have had a protective effect, including LPS-induced shock (Garcia Soriano et al. 2001), septic shock (Liaudet et al. 2001), lung inflammation (Liaudet et al. 2002), arthritis and colitis (Mabley et al. 2003b). Increased MIP-1 $\alpha$ levels are pivotal in the pathogenesis of various inflammatory diseases, and inhibiting its production/ expression may, in part, explain why purines are protective in such a wide variety of inflammatory conditions.

The effects of inosine on inflammatory cytokine and chemokine production were proposed to be mediated, at least in part, by adenosine receptor-related mechanisms (Hasko et al. 2000) and this may also be true for INO-2002. Activation of the adenosine $\mathrm{A}_{2 \mathrm{a}}$ receptor downregulates inflammation and protect against tissue damage (Ohta \& Sitkovsky 2001) and inosine's inhibitory effect on inflammatory cytokine production is mediated in part by activation of this adenosine receptor (Hasko et al. 2000). Recently, we have demonstrated that adenosine receptor activation ameliorates type I diabetes, as adenosine- $5^{\prime}-\mathrm{N}$-ethylcarboxanide (NECA), a non-selective adenosine receptor agonist, protects against MLDS- and cyclophosphamide-induced diabetes in NOD mice (Nemeth et al. 2007). This protection was associated with decreased pancreatic levels of Th1 cytokines, IL-12, TNF- $\alpha$ and IFN- $\gamma$, and the chemokine MIP-1 $\alpha$ (Nemeth et al. 2007). Interestingly, using both specific receptor antagonists and transgenic knockout mice, the protection by adenosine against type I diabetes was found to be mediated through activation of the $A_{2 b}$ receptor subtype rather than the $A_{2 a}$ (Nemeth et al. 2007), implicating both $A_{2 a}$ and $A_{2 b}$ receptor subtypes in adenosines modulation of the inflammatory system. The results obtained using adenosine and its receptor agonists in models of type I diabetes mimic those observed with both inosine and INO-2002, suggesting a role for $A_{2 b}$ receptor activation in inosine/INO-2002mediated protection. It is conceivable that in modifying inosine to produce the analogue INO-2002 we may have made it a more effective agonist for the $\mathrm{A}_{2 \mathrm{~b}}$ receptor subtype, which may explain why INO-2002 is more potent than inosine in protecting against type I diabetes.

Other possible mechanisms include affecting poly (ADPribose) polymerase (PARP) activity, which inosine inhibits only at millimolar concentrations (Virag \& Szabo 2001). PARP overactivation has been implicated in the pathogenesis of various forms of inflammation including autoimmune diabetes (Mabley et al. 2001a,b, Suarez-Pinzon et al. 2003). Inosine is also 
metabolized to uric acid, which has been demonstrated to be a scavenger of free radicals, including peroxynitrite (Ames et al. 1981, Becker et al. 1989). Peroxynitrite formation has been implicated in $\beta$-cell death resulting in development of type I diabetes (Lakey et al. 2001, Suarez-Pinzon et al. 2001); administration of peroxynitrite scavenger compounds has proved effective in preventing type I diabetes in a variety of animal models (Szabó et al. 2002, Mabley et al. 2004). However, based on the structure of INO-2002 and its inability to be metabolized, we can surmise that both these mechanisms are unlikely to mediate the protective effects of INO-2002 in type I diabetes. With the modification of inosine to produce INO-2002, it is unlikely we made it a more potent PARP inhibitor and it is very unlikely that we achieved millimolar concentrations of INO-2002 in the pancreas with doses of $30 \mathrm{mg} / \mathrm{kg}$ per day, hence PARP inhibition can be considered to be only a minor effect of INO-2002 and not significant in its protective action. Previous studies with INO2002 have shown it to be resistant to metabolism by both purine nucleoside phosphorylase and $5^{\prime}$-nucleotidase hence incapable of forming hypoxanthine, a substrate for xanthine oxidase to produce uric acid. Therefore, INO-2002 will not increase uric acid levels to levels where scavenging of reactive species, such as peroxynitrite, is relevant for INO-2002-mediated protection in type I diabetes.

In conclusion, we have demonstrated that an analogue of inosine provides protection from type I diabetes in two animal models. INO-2002 has proven more efficacious than inosine not only in type I diabetes but also in other inflammatory diseases such as arthritis, colitis and adult respiratory distress syndrome. INO-2002 is also a very safe drug that, similarly to inosine, shows no toxicity at doses much larger, over five times, as would be used therapeutically. INO-2002's mechanism of protection is via effects on both chemokine and cytokine and both Th1 and Th2 expression likely mediated through activation of the adenosine $A_{2 b}$ receptor. With purines having an excellent safety profile, clinical trials may show that stable purine analogues, such as INO-2002, are effective in treating many inflammatory diseases.

\section{Declaration of interest}

GJS, ALS \& GS were the founders of Inotek Pharmaceuticals, the developer of INO-2002, and all own stock in the company. KGKM and WW are employees of Inotek Pharmaceuticals.

\section{Funding}

This study was supported by a grant from the National Institutes of Health (1R43 DK59676) to G J S.

\section{References}

Allison AC \& Eugui EM 2000 Mycophenolate mofetil and its mechanisms of action. Immunopharmacology 47 85-118.

Ames BN, Cathcart R, Schwiers E \& Hochstein P 1981 Uric acid provides an antioxidant defense in humans against oxidant- and radical-caused aging and cancer: a hypothesis. PNAS 78 6858-6862.
Atkinson MA \& Leiter EH 1999 The NOD mouse model of type 1 diabetes: as good as it gets? Nature Medicine 5 601-604.

Bach J-F 1994 Insulin-dependent diabetes mellitus as an autoimmune disease. Endocrine Reviews 15 516-542.

Becker BF, Reinholz N, Ozcelik T, Leipert B \& Gerlach E 1989 Uric acid as radical scavenger and antioxidant in the heart. Pflugers Archiv 415 $127-135$.

Bradford MM 1976 A rapid and sensitive method for the quantification of microgram quantities of protein utilizing the principle of protein-dye binding. Analytical Biochemistry 72 248-254.

Cameron MJ, Arreaza GA, Grattan M, Meagher C, Sharif S, Burdick MD, Strieter RM, Cook DN \& Delovitch TL 2000 Differential expression of CC chemokines and the CCR5 receptor in the pancreas is associated with progression to type I diabetes. Journal of Immunology $\mathbf{1 6 5}$ 1102-1110.

Campoli-Richards DM, Sorkin EM \& Heel RC 1986 Inosine pranobex. A preliminary review of its pharmacodynamic and pharmacokinetic properties, and therapeutic efficacy. Drugs 32 383-424.

Chatenoud L, Primo J \& Bach JF 1997 CD3 antibody-induced dominant self tolerance in overtly diabetic NOD mice. Journal of Immunology 158 2947-2954.

Darlington DN \& Gann DS 2005 Inosine infusion prevents mortality in endotoxic shock. Journal of Trauma 59 1432-1435 (discussion 1435).

Eizirik DL \& Darville MI $2001 \beta$-cell apoptosis and defense mechanisms: lessons from type 1 diabetes. Diabetes 50 (Suppl 1) S64-S69.

Garcia Soriano F, Liaudet L, Marton A, Hasko G, Batista Lorigados C, Deitch EA \& Szabo C 2001 Inosine improves gut permeability and vascular reactivity in endotoxic shock. Critical Care Medicine 29 703-708.

Harlan DM, Barnett MA, Abe R, Pechhold K, Patterson NB, Gray GS \& June CH 1995 Very-low-dose streptozotocin induces diabetes in insulin promoter-mB7-1 transgenic mice. Diabetes 44 816-823.

Hasko G, Kuhel DG, Nemeth ZH, Mabley JG, Stachlewitz RF, Virag L, Lohinai Z, Southan GJ, Salzman AL \& Szabo C 2000 Inosine inhibits inflammatory cytokine production by a posttranscriptional mechanism and protects against endotoxin-induced shock. Journal of Immunology 164 1013-1019.

Hasko G, Sitkovsky MV \& Szabo C 2004 Immunomodulatory and neuroprotective effects of inosine. Trends in Pharmacological Sciences $\mathbf{2 5}$ 152-157.

Lakey JR, Suarez-Pinzon WL, Strynadka K, Korbutt GS, Rajotte RV, Mabley JG, Szabo C \& Rabinovitch A 2001 Peroxynitrite is a mediator of cytokineinduced destruction of human pancreatic islet $\beta$-cells. Laboratory Investigation 81 1683-1692.

Li P, Ogino K, Hoshikawa Y, Morisaki H, Cheng J, Toyama K, Morisaki T, Hashimoto K, Ninomiya H, Tomikura-Shimoyama Y et al. 2007 Remote reperfusion lung injury is associated with AMP deaminase 3 activation and attenuated by inosine monophosphate. Circulation Journal 71 591-596.

Liaudet L, Mabley JG, Soriano FG, Pacher P, Marton A, Hasko G \& Szabo C 2001 Inosine reduces systemic inflammation and improves survival in septic shock induced by cecal ligation and puncture. American Journal of Respiratory and Critical Care Medicine 164 1213-1220.

Liaudet L, Mabley JG, Pacher P, Virag L, Soriano FG, Marton A, Hasko G, Deitch EA \& Szabo C 2002 Inosine exerts a broad range of antiinflammatory effects in a murine model of acute lung injury. Annals of Surgery $\mathbf{2 3 5}$ 568-578.

Like AA \& Rossini AA 1976 Streptozotocin-induced pancreatic insulitis: new model of diabetes mellitus. Science 193 415-417.

Mabley JG, Jagtap P, Perretti M, Getting SJ, Salzman AL, Virag L, Szabo E, Soriano FG, Liaudet L, Abdelkarim GE et al. 2001 a Anti-inflammatory effects of a novel, potent inhibitor of poly (ADP-ribose) polymerase. Inflammation Research 50 561-569.

Mabley JG, Suarez-Pinzon WL, Hasko G, Salzman AL, Rabinovitch A, Kun E \& Szabo C 2001b Inhibition of poly (ADP-ribose) synthetase by gene disruption or inhibition with 5-iodo-6-amino-1,2-benzopyrone protects mice from multiple-low-dose-streptozotocin-induced diabetes. British Journal of Pharmacology 133 909-919. 
Mabley JG, Virag L \& Szabo C 2002 Role of poly (ADP-ribose) polymerase activation in the pathogenesis of diabetes mellitus and diabetic vascular dysfunction. In PARP as a Therapeutic Target, pp 277-319. Ed. J Zhang. London: CRC Press.

Mabley JG, Pacher P, Liaudet L, Soriano FG, Hasko G, Marton A, Szabo C \& Salzman AL 2003a Inosine reduces inflammation and improves survival in a murine model of colitis. American Journal of Physiology. Gastrointestinal and Liver Physiology 284 G138-G144.

Mabley JG, Rabinovitch A, Suarez-Pinzon W, Hasko G, Pacher P, Power R, Southan G, Salzman A \& Szabo C $2003 b$ Inosine protects against the development of diabetes in multiple-low-dose streptozotocin and nonobese diabetic mouse models of type 1 diabetes. Molecular Medicine 9 96-104.

Mabley JG, Southan GJ, Salzman AL \& Szabo C 2004 The combined inducible nitric oxide synthase inhibitor and free radical scavenger guanidinoethyldisulfide prevents multiple low-dose streptozotocin-induced diabetes in vivo and interleukin-1 $\beta$-induced suppression of islet insulin secretion in vitro. Pancreas 28 E39-E44.

Mabley JG, Pacher P, Deb A, Wallace R, Elder RH \& Szabo C 2005 Potential role for 8-oxoguanine DNA glycosylase in regulating inflammation. FASEB Journal 19 290-292.

Maksimovic-Ivanic D, Trajkovic V, Miljkovic DJ, Mostarica Stojkovic M \& Stosic-Grujicic S 2002 Down-regulation of multiple low dose streptozotocin-induced diabetes by mycophenolate mofetil. Clinical and Experimental Immunology 129 214-223.

Martin AP, Alexander-Brett JM, Canasto-Chibuque C, Garin A, Bromberg JS, Fremont DH \& Lira SA 2007 The chemokine binding protein M3 prevents diabetes induced by multiple low doses of streptozotocin. Journal of Immunology 178 4623-4631.

Marton A, Pacher P, Murthy KG, Nemeth ZH, Hasko G \& Szabo C 2001 Anti-inflammatory effects of inosine in human monocytes, neutrophils and epithelial cells in vitro. International Journal of Molecular Medicine 8 617-621.

Nemeth ZH, Bleich D, Csoka B, Pacher P, Mabley JG, Himer L, Vizi ES, Deitch EA, Szabo C, Cronstein BN et al. 2007 Adenosine receptor activation ameliorates type 1 diabetes. FASEB Journal 21 2379-2388.

Ohta A \& Sitkovsky M 2001 Role of G-protein-coupled adenosine receptors in downregulation of inflammation and protection from tissue damage. Nature 414 916-920.

Qiu FH, Wada K, Stahl GL \& Serhan CN 2000 IMP and AMP deaminase in reperfusion injury down-regulates neutrophil recruitment. PNAS $\mathbf{9 7}$ $4267-4272$.

Rabinovitch A 1998 An update on cytokines in the pathogenesis of insulindependent diabetes mellitus. Diabetes/Metabolism Reviews 14 129-151.

Rabinovitch A \& Suarez-Pinzon WL 1998 Cytokines and their roles in pancreatic islet beta-cell destruction and insulin-dependent diabetes mellitus. Biochemical Pharmacology 55 1139-1149.

Rabinovitch A, Suarez-Pinzon WL \& Sorensen O 1996 Interleukin 12 mRNA expression in islets correlates with beta-cell destruction in NOD mice. Journal of Autoimmunity 9 645-651.

Rossini AA, Williams RM, Appel MC \& Like AA 1978 Complete protection from low-dose streptozotocin-induced diabetes in mice. Nature $\mathbf{2 7 6}$ 182-184.
Rothe H, O'Hara RM Jr, Martin S \& Kolb H 1997 Suppression of cyclophosphamide induced diabetes development and pancreatic Th1 reactivity in NOD mice treated with the interleukin (IL)- 12 antagonist IL-12(p40)2. Diabetologia 40 641-646.

Ryu S, Kodama S, Ryu K, Schoenfeld DA \& Faustman DL 2001 Reversal of established autoimmune diabetes by restoration of endogenous $\beta$-cell function. Journal of Clinical Investigation 108 63-72.

Schneider S \& Klein HH 2005 Inosine improves islet xenograft survival in immunocompetent diabetic mice. European Journal of Medical Research 10 283-286.

Sia C 2005 Imbalance in th cell polarization and its relevance in type 1 diabetes mellitus. Review of Diabetic Studies 2 182-186.

Stosic-Grujicic S, Maksimovic-Ivanic D, Miljkovic D, Trajkovic V, Lukic M \& Mostarica Stojkovic M 2002 Inhibition of autoimmune diabetes by mycophenolate mofetil is associated with down-regulation of TH1 cytokine-induced apoptosis in the target tissue. Transplantation Proceedings 34 2955-2957.

Suarez-Pinzon WL, Mabley JG, Strynadka K, Power RF, Szabo C \& Rabinovitch A 2001 An inhibitor of inducible nitric oxide synthase and scavenger of peroxynitrite prevents diabetes development in nod mice. Journal of Autoimmunity 16 449-455.

Suarez-Pinzon WL, Mabley JG, Power R, Szabo C \& Rabinovitch A 2003 Poly (ADP-ribose) polymerase inhibition prevents spontaneous and recurrent autoimmune diabetes in NOD mice by inducing apoptosis of islet-infiltrating leukocytes. Diabetes 52 1683-1688.

Szabó C, Mabley JG, Moeller SM, Shimanovich R, Pacher P, Virag L, Soriano FG, Van Duzer JH, Williams W, Salzman AL et al. 2002 Part I: pathogenetic role of peroxynitrite in the development of diabetes and diabetic vascular complications: studies with FP15, a novel potent peroxynitrite decomposition catalyst. Molecular Medicine 8 571-580.

Szabo G, Stumpf N, Radovits T, Sonnenberg K, Gero D, Hagl S, Szabo C \& Bahrle S 2006 Effects of inosine on reperfusion injury after heart transplantation. European Journal of Cardio-Thoracic Surgery 30 96-102.

Szkudelski T 2001 The mechanism of alloxan and streptozotocin action in B cells of the rat pancreas. Physiological Research 50 537-546.

Virag L \& Szabo C 2001 Purines inhibit poly(ADP-ribose) polymerase activation and modulate oxidant-induced cell death. FASEB Journal 15 99-107.

Ward SG, Bacon K \& Westwick J 1998 Chemokines and T lymphocytes: more than an attraction. Immunity $91-11$.

Wybran J, Famaey JP \& Appelboom T 1981 Inosiplex: a novel treatment in rheumatoid arthritis? Journal of Rheumatology 8 643-646.

Received in final form 28 May 2008
Accepted 18 June 2008

Made available online as an Accepted Preprint 18 June 2008 